\title{
Lectin-Like Bacteriocins
}

\author{
Maarten G. K. Ghequire ${ }^{1 *}$, Başak Öztürk ${ }^{2 \dagger}$ and René De Mot ${ }^{1 \neq}$ \\ ${ }^{1}$ Centre of Microbial and Plant Genetics, KU Leuven, Leuven, Belgium, ${ }^{2}$ Leibniz-Institut DSMZ-Deutsche Sammlung von \\ Mikroorganismen und Zellkulturen, Braunschweig, Germany
}

\section{OPEN ACCESS}

Edited by:

Natalia V. Kirienko,

Rice University, United States

Reviewed by:

Marina G. Kalyuzhanaya, San Diego State University,

United States

Rhys William Grinter University of Birmingham,

United Kingdom

*Correspondence:

Maarten G. K. Ghequire maarten.ghequire@kuleuven.be; maarten.ghequire@biw.kuleuven.be orcid.org/0000-0002-5577-7277

torcid.org/0000-0002-8687-3210

forcid.org/0000-0002-0030-9441

Specialty section:

This article was submitted to Antimicrobials, Resistance and Chemotherapy,

a section of the journal

Frontiers in Microbiology

Received: 25 July 2018 Accepted: 23 October 2018 Published: 12 November 2018

Citation:

Ghequire MGK, Öztürk $B$ and De Mot R (2018) Lectin-Like Bacteriocins

Front. Microbiol. 9:2706. doi: 10.3389/fmicb.2018.02706
Bacteria produce a diverse array of antagonistic compounds to restrict growth of microbial rivals. Contributing to this warfare are bacteriocins: secreted antibacterial peptides, proteins and multi-protein complexes. These compounds typically eliminate competitors closely related to the producer. Lectin-like bacteriocins (LIpAs) constitute a distinct class of such proteins, produced by Pseudomonas as well as some other proteobacterial genera. LIpAs share a common architecture consisting of two B-lectin domains, followed by a short carboxy-terminal extension. Two surfaceexposed moieties on susceptible Pseudomonas cells are targeted by the respective lectin modules. The carboxy-terminal domain binds D-rhamnose residues present in the lipopolysaccharide layer, whereas the amino-terminal domain interacts with a polymorphic external loop of the outer-membrane protein insertase BamA, hence determining selectivity. The absence of a toxin-immunity module as found in modular bacteriocins and other polymorphic toxin systems, hints toward a novel mode of killing initiated at the cellular surface, not requiring bacteriocin import. Despite significant progress in understanding the function of LIpAs, outstanding questions include the secretion machinery recruited by lectin-like bacteriocins for their release, as well as a better understanding of the environmental signals initiating their expression.

Keywords: LIpA, L-type pyocin, BAM complex, protein antibiotic, bacterial antagonism

\section{INTRODUCTION}

Pseudomonads produce a diverse set of antagonism-mediating compounds that assist the elimination of rival microorganisms. A major subset of molecules contributing to this microbial fight are bacteriocins, ribosomally encoded antibacterial peptides and proteins that target bacteria closely related to the producing strain (Ghequire and De Mot, 2014). Bacteriocins assigned to different classes, based on molecular size and architecture, have been identified in a variety of Pseudomonas species (Lavermicocca et al., 2002; Parret et al., 2003, 2005; Barreteau et al., 2009; Fischer et al., 2012; Godino et al., 2015; Hockett et al., 2015). To date, research has primarily focused on Pseudomonas aeruginosa bacteriocins (termed pyocins) (Michel-Briand and Baysse, 2002). The bacteriocin armamentarium owned by pseudomonads varies from strain to strain (Ghequire and De Mot, 2014; Sharp et al., 2017). For different classes of bacteriocins, an evolutionary advantage has been demonstrated for bacteria secreting such compounds (Inglis et al., 2014; Ghoul et al., 2015; Godino et al., 2015; Dorosky et al., 2017; Príncipe et al., 2018).

Four main groups of Pseudomonas bacteriocins have been identified so far, all of which equally occur in other bacterial genera: tailocins, modular bacteriocins, B-type microcins and lectin-like bacteriocins (Supplementary Table S1). (i) Tailocins resemble contractile (R-type) or flexible (Ftype) bacteriophage tails (Ghequire and De Mot, 2015; Scholl, 2017). Acquired from different phage 
sources, these high molecular-weight particles are synthesized from large gene clusters and are functional stand-alone units, lacking an accompanying phage head structure. (ii) Modular (S-type) bacteriocins represent a heterogeneous group of polymorphic toxins, and include a receptor-binding domain, a moiety assisting in membrane passage of target cells and a toxin domain (Ghequire and De Mot, 2014; Jamet and Nassif, 2015; Sharp et al., 2017). Self-inhibition due to toxin activity in bacteriocin producers is avoided by co-expression of dedicated immunity genes. These immunity partners form specific and high-affinity complexes with their cognate toxin domains, or reside in the cytoplasmic membrane to temporarily inhibit toxin activity during secretion (Rasouliha et al., 2013; Joshi et al., 2015; Ghequire et al., 2017b). To gain access to targeted pseudomonads, S-type bacteriocins take advantage of TonB-dependent outermembrane proteins (White et al., 2017). (iii) B-type microcins are post-translationally modified peptides, interfering with DNA gyrase (Metelev et al., 2013). (iv) Lectin-like (further abbreviated as L-type) bacteriocins are composed of two monocot mannosebinding lectin domains and represent a fourth major class of Pseudomonas bacteriocins (Parret et al., 2003), with an unknown mode of action. In this review, we provide an overview summarizing current knowledge on the latter bacteriocin type, with emphasis on outstanding research questions.

\section{A SUGAR-BINDING TANDEM DESIGNED TO KILL}

Originally identified in banana rhizosphere isolate Pseudomonas putida BW11M1 (recently reclassified as Pseudomonas mosselii BW11M1) (Parret et al., 2003; Ghequire et al., 2016), the first lectin-like bacteriocin was termed LlpA (lectin-like putidacin $\underline{\mathrm{A}}$ ), and shown to possess selective genus-specific antagonistic activity, characteristic of bactericidal action. Later, LlpA bacteriocins were characterized in a number of other Pseudomonas species as well: Pseudomonas protegens (Parret et al., 2005), Pseudomonas syringae (Ghequire et al., 2012a) and P. aeruginosa (Ghequire et al., 2014; McCaughey et al., 2014) (Table 1). These bacteriocins are called "lectin-like" because all share an organization comprising two "monocot mannose-binding lectin" (MMBL) domains (B-lectin, Pfam PF01453), instead of a toxin-immunity module that is usually present in bacteriocins of similar size. The B-lectin domain is abundant in (monocot) plants (Van Damme et al., 1991; Pang et al., 2003; Gao et al., 2011; Pereira et al., 2015), but has also been found in fish (Tsutsui et al., 2003; de Santana Evangelista et al., 2009; Park et al., 2016; Arasu et al., 2017), fungi (Fouquaert et al., 2011; Shimokawa et al., 2012), slime molds (Barre et al., 1999) and sponges (Wiens et al., 2006). In those organisms a variety of antagonistic functions have been assigned to these lectins, including antifungal, antiviral and nematicidal activities (Ghequire et al., 2012b; Wu and Bao, 2013). A lectin-type bacteriocin with a distinct domain organization has been identified in a Gram-positive bacterium: albusin B of Ruminococcus albus 7 targets Ruminococcus flavefaciens, and consists of a B-lectin domain followed by a peptidase M15 domain (PF08291) (Chen et al., 2004). Genes encoding albusin B-like proteins have been retrieved in many other $R$. albus strains (Azevedo et al., 2015).

The 3D structure of LlpA from strain BW11M1 (LlpA $\left.A_{B W 11 M 1}\right)$ confirmed the architecture of two B-lectin domains as studied in monocot plants (Wright et al., 2000). Each module is stabilized by a central tryptophan triad. A short $\beta$-hairpin extension is present at the carboxy-terminus (Figure 1), but is absent from plant lectins (Ghequire et al., 2013b). The two domains form a rigid tandem due to $\beta$-strand swapping and intramolecular interactions (Figure 1). Such swapping can be equally noticed in dimers of single-domain MMBLs and tandem MMBLs from plants, though the relative orientation of each of the lectin domains in LlpAs may differ compared to (dimeric and tandem) MMBLs from plants (discussed in more detail in Ghequire et al., 2013b; McCaughey et al., 2014) (Figure 1). Plant B-lectin modules contain three carbohydrate-binding motifs with a consensus sequence QxDxNxVxY (Ghequire et al., 2012b; Wu and Bao, 2013), most of which are usually active, whereas these lectin motifs are often harder to discern in LlpAs (Ghequire et al., 2014). Motif conservation is mainly present in LlpA's carboxy-terminal lectin domain. Sugar-binding properties are indeed linked to the latter domain, since intact $\mathrm{QxDxNxVxY}$ lectin motifs proved necessary to obtain a fully active bacteriocin. Nevertheless the affinity of LlpA $A_{B W 11 M 1}$ for D-mannose and oligomannosides was observed to be quite low (Ghequire et al., 2013b), raising doubts about its biological significance. This issue was resolved after elucidating the structure of a lectin-like bacteriocin from cystic fibrosis isolate $P$. aeruginosa C1433, pyocin L1, that targets $P$. aeruginosa model strain PAO1 (McCaughey et al., 2014) (Figure 1). This L-type bacteriocin adopts a similar fold as LlpA $A_{B W 11 M 1}$, but rather than binding D-mannose, pyocin L1 displays a much higher affinity for D-rhamnose, a 6-deoxy-D-mannose that is omnipresent in the common polysaccharide antigen (CPA) of $P$. aeruginosa (Lam et al., 2011). Two lectin motifs in the carboxy-terminal domain of pyocin L1 were ultimately shown to assist in this D-rhamnose binding, which equally appeared to be the case for LlpABW11M1 (McCaughey et al., 2014). Following crystal soaks of LlpA $A_{B W 11 M 1}$ with D-mannose, it was initially unclear whether one or two lectin motifs contributed to the protein's sugar-binding properties (Ghequire et al., 2013b). More recently a third LlpA, LlpA1 $1_{\mathrm{Pf}-5}$ from $P$. protegens Pf-5, was equally found to depend on CPA for cellular killing (Ghequire et al., 2018b), suggesting that CPA likely is a common receptor among Pseudomonas LlpAs for target cell attachment. Carbohydrates present in O-antigen-specific lipopolysaccharide (LPS) are also used for cell surface docking by the tail fibers of R-type tailocins (Köhler et al., 2010; Kocincová and Lam, 2013; Ghequire et al., 2015; Buth et al., 2018), and some modular pyocins equally bind to CPA for target anchoring (McCaughey et al., 2016a). From a bacteriocin producer point of view, such targeting of LPS is a very attractive and effective strategy, since competitors become more susceptible to killing by detergents and permeable to antibiotics when attempting to escape from bacteriocin killing by LPS assembly loss (Ruiz et al., 2006; Falchi et al., 2018). 
TABLE 1 | Overview of functionally characterized proteobacterial LIpA bacteriocins.

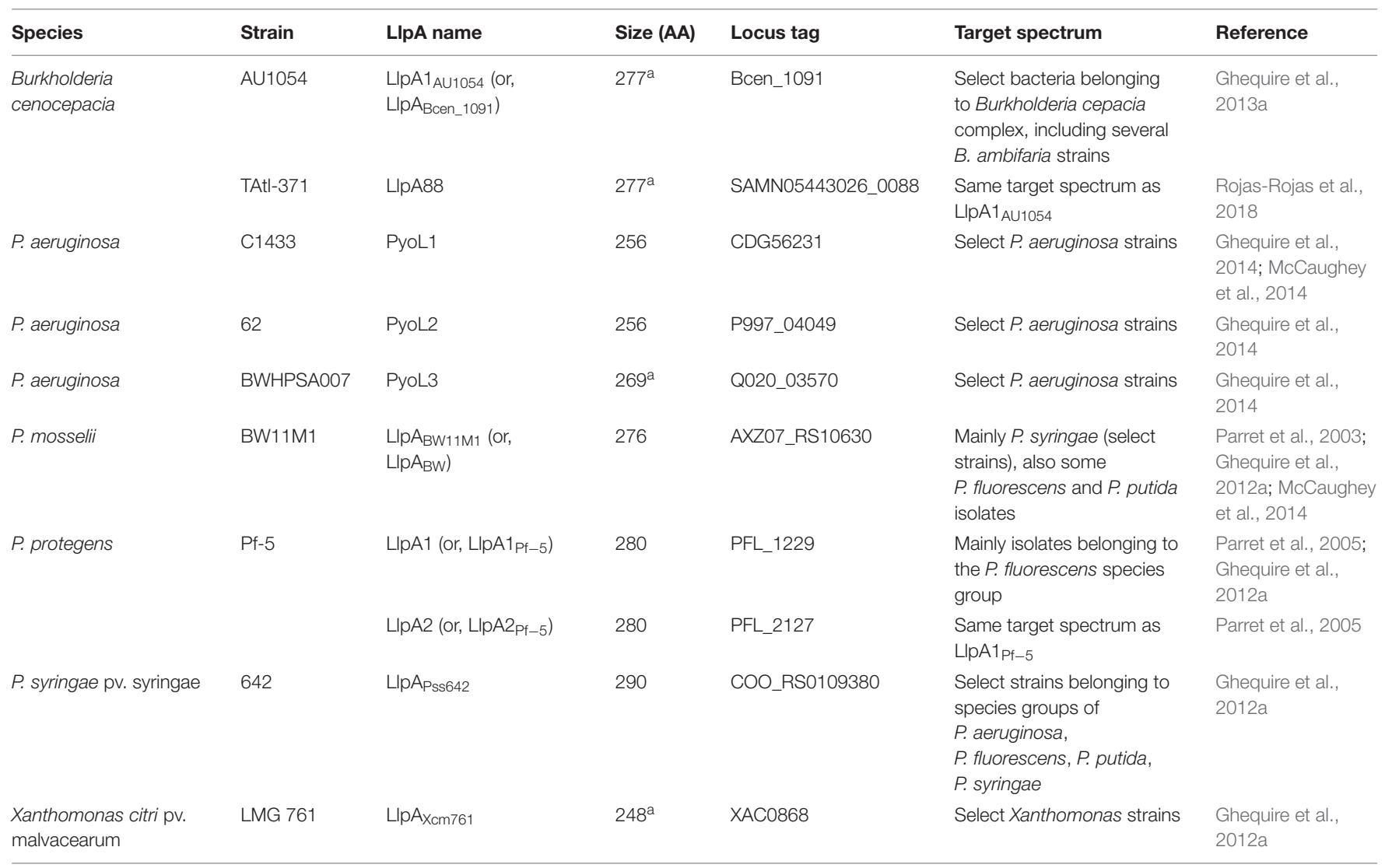

${ }^{a}$ size of the mature protein after cleavage of predicted Sec-dependent signal peptide.
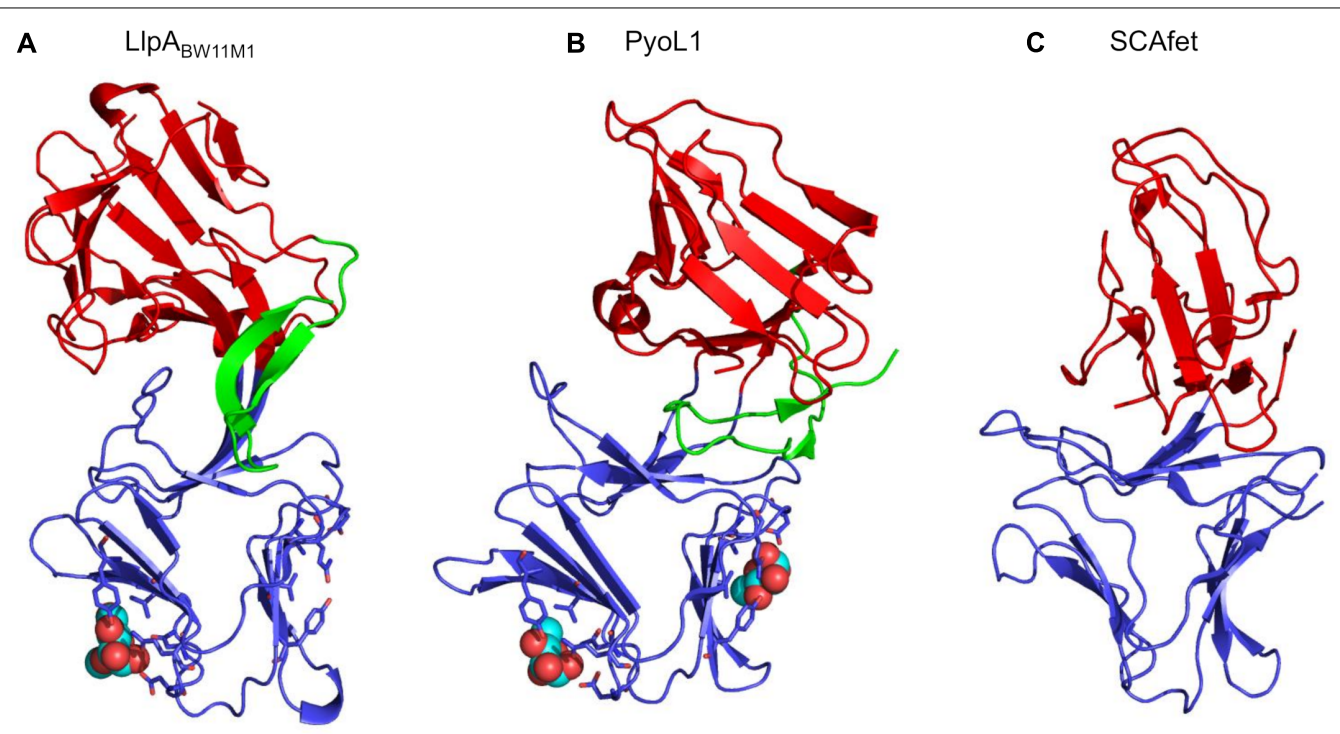

FIGURE 1 | Ribbon diagram of structures from (A) LIpA from P. mosselii BW11M1 (LIPABW11M1, PDB 3M7J), (B) LIpA from P. aeruginosa C1433 (PyoL1, PDB 4LED), (C) tandem MMBL plant protein SCAfet from Scilla campanulata (PDB 1DLP). The amino-terminal lectin domains are shown in red, the carboxy-terminal lectin domains in blue, and the carboxy-terminal extensions (absent in B-lectins from plants) in green. Side chains of coordinating residues constituting the D-rhamnose-binding lectin motifs in the carboxy-terminal lectin domains of LIPABW11M1 and PyoL1 are shown as sticks. Methyl-mannose and D-rhamnose bound to

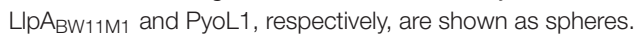


Via activity/specificity assays using engineered LlpA chimers, it was further found that the amino-terminal lectin domain of LlpA accounts for target selection, regardless of the LPS-binding carboxy-terminal lectin module being present (Ghequire et al., 2013b). Phylogenetic analysis of individual lectin domains of characterized and putative LlpAs shows a clear clustering of each of the domains (Figure $\mathbf{2}$ and Supplementary Figure S1) (Ghequire et al., 2012b, 2014), which is in support of this domain-function dichotomy. Comparatively higher sequence conservation of the carboxy-terminal lectin domains [48\% pairwise amino acid (AA) sequence identity (seq id)] results in a tighter clustering and advocates a more general function of the C-terminal lectin domain with regard to CPA binding (see above). Conversely, the amino-terminal domains have diverged more ( $\sim 39 \%$ pairwise AA seq id), and apparently evolved to hit different subsets of pseudomonads. Highly similar lectin-like pyocins PyoL1 and PyoL2 (86\% pairwise AA seq id) display a divergent target spectrum, and differential bacteriocin residues primarily cluster at one patch of their amino-terminal lectin domains (Ghequire et al., 2014), which again supports the target-selective function of the aminoterminal lectin domain.

\section{VANDALIZING AN ESSENTIAL OUTER-MEMBRANE PROTEIN ASSEMBLY MACHINERY}

Mutants of $P$. aeruginosa PAO1 defective in CPA biosynthesis do not become fully resistant to pyocin L1 killing (McCaughey et al., 2014). This suggests that a second receptor for L-type bacteriocin bactericidal action has to exist. Since CPA binding on its own cannot account for a cell death mechanism and given the lack of a distinct toxin domain, as present in modular bacteriocins, this was also expected. Recently, it was found that spontaneous mutants of $P$. fluorescens Pf0-1 become resistant to $\mathrm{LlpA} 1_{\mathrm{Pf}-5}$ killing when mutated in a surfaceexposed loop of outer membrane protein (OMP) insertase BamA (Ghequire et al., 2018b). This essential protein consists of five polypeptide transport-associated (POTRA) domains and a

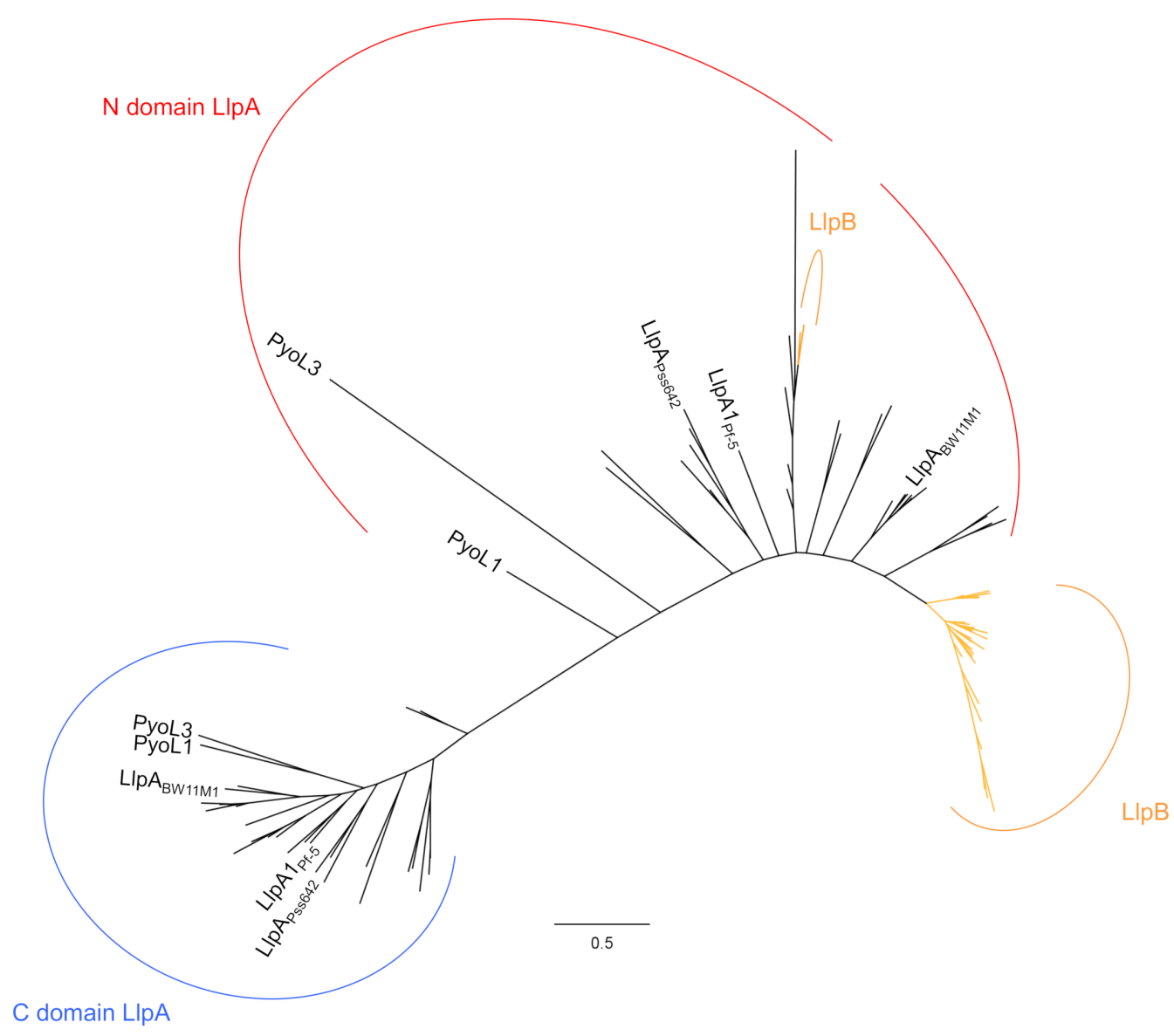

FIGURE 2 | Maximum likelihood phylogenetic tree of individual B-lectin modules from Pseudomonas LIpAs and LIpBs. Amino-terminal domains (N) and carboxy-terminal domains (C) of LlpAs, and lectin domains of LIpBs are depicted by (a) red, blue and orange arc(s), respectively. Lectin domains originating from highly similar LIpA/LIpB sequences (> 80\% pairwise sequence id) are included as a single representative. Only characterized LIpAs are specified; species codes of other LIpAs and LIpBs, and bootstrap values (percentages of 1000 replicates) are not shown for clear distinction. A phylogenetic tree with complete annotations and bootstrap values is shown in the supplement (Supplementary Figure S1). Scale bar represents 0.5 substitutions per site. 
carboxy-terminal $\beta$-barrel in the outer membrane, and interacts with lipoproteins BamB, BamC, BamD and BamE to constitute the BAM complex (Leyton et al., 2015; Noinaj et al., 2017). This machinery acts as the main catalyst for the insertion of new OMPs in the outer-membrane layer, with a key function attributed to BamA to partially unzip and create an open gate for a nascent OMP (Noinaj et al., 2014). The surfaceexposed side of BamA is covered by three large loops (loops 4, 6, and 7) forming a dome-like structure (Ni et al., 2014). Mutations (single nucleotide polymorphisms, small in-frame deletions) in loop 6 (L6), allowed escape from LlpA1 $1_{\mathrm{Pf}-5}$ killing. In a similar experimental set-up using the reference strain PAO1, mutations in this same BamA loop were detected for spontaneous mutants resistant to PyoL1 killing (Ghequire et al., 2018b).

Depending on the Pseudomonas species group of interest, conservation in BamA may be moderate to very high. In $P$. aeruginosa in particular, BamA sequence conservation is nearly perfect, except for surface-exposed L6, the same loop in which mutations yielding bacteriocin resistance were detected. Furthermore, only a limited set of L6 sequence variants seem to exist in nature, that vary depending on the Pseudomonas species (group). Interestingly, a strong correlation between L6 sequence type and susceptibility to a certain LlpA was demonstrated for pyocins L1 and L2, and LlpABW11M1 (Ghequire et al., 2018b). BamA indeed appears to be the key selectivity partner of LlpAs, since susceptibility to a particular LlpA is conferred upon an otherwise LlpA-resistant Pseudomonas by expression of a BamA with the corresponding LlpA-compatible L6 loop. LlpA producers escape from self-inhibition by expressing a BamA equipped with a different L6 than the one they are targeting (Ghequire et al., 2018b), an elegant mechanism preventing kin killing without the need for an immunity protein. Whereas modular bacteriocins typically display species-specific antagonism (Barreteau et al., 2009; Ghequire and De Mot, 2014; Godino et al., 2015; Ghequire et al., 2017a; Hockett et al., 2017), lectin-like bacteriocins (may) show genus-specific killing, which is explained by the occurrence of certain L6 sequence types in different Pseudomonas species (Ghequire et al., 2012a, 2018b). Taken together, the variation in surface-exposed loops of BamA proteins explains why different LlpAs target different subsets of pseudomonads. An interesting observation is that some effectors of contact-dependent growth inhibition (CDI) systems - polymorphic toxins released via a Type V secretion system mediating cell death by cell-to-cell contact (Willett et al., 2015; Chassaing and Cascales, 2018) - equally take advantage of BamA as a surface receptor (Aoki et al., 2008). As is the case for LlpAs, sequence polymorphism of BamA was found to determine susceptibility, although depending on two surface-exposed loops, L6 and L7 (Ruhe et al., 2013).

At this point, the molecular details of the interaction between LlpA and (L6 of) BamA remain elusive, and therefore it is currently unclear how exactly LlpA impairs the BAM function.
A
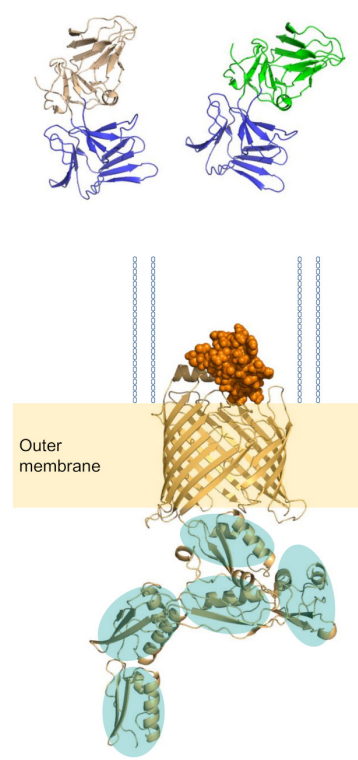

B

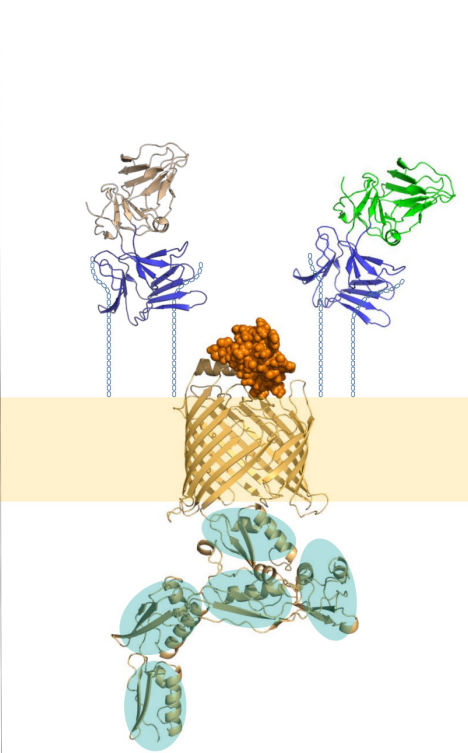

C
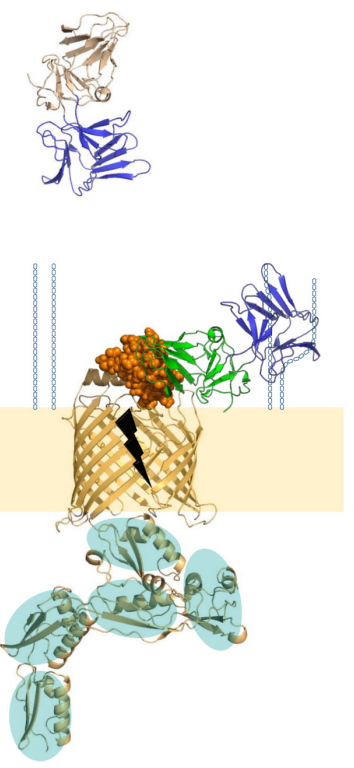

FIGURE 3 | Proposed model of LIpA in interaction with its cell-surface receptors. (A) For BamA, the barrel in the outer membrane is shown in cartoon (orange), the surface-exposed loop L6 as orange spheres, and the five POTRA domains in the periplasm (cartoon, orange) are highlighted by teal ovals. The BamA sequence of $P$. aeruginosa PAO1 was used to construct the 3D-model (i-TASSER; https://zhanglab.ccmb.med.umich.edu/l-TASSER/). D-rhamnose units that are part of CPA are shown as blue hexagons (O-specific antigen of the lipopolysaccharide is not shown). CPA-binding domains of lectin-like bacteriocins (C-domains) are shown in blue, and amino-terminal lectin domains of LIpAs with different specificities are shown in wheat and green. (B) Lectin moieties in the carboxy-terminal domains of lectin-like bacteriocins attach to D-rhamnose residues present in CPA. (C) After/concurrent with CPA attachment, a stable bacteriocin-target interaction arises if L6 of BamA is recognized by LIpA. Killing action (black thunderbolt) is exerted in an unknown manner. 
It should be underlined that BamA is a dynamic protein given its role in OMP assembly: the integration of (a) new $\beta$-sheet(s) of a nascent OMP requires a destabilized and structurally rearranged seam of the BamA $\beta$-barrel (Doerner and Sousa, 2017). Conceivably, LlpA may impair the function of this lateral gate/exit pore located at the outer-membrane-periplasm interface by hindering structural reorganization, subsequently leading to a (lethal) downstream stress response (Figure 3). A role for the carboxy-terminal extension of LlpAs may also be anticipated since this stretch contains a number of hydrophobic residues that may mimic an elongated $\beta$-sheet (Figure 1) (Ghequire et al., 2013b; McCaughey et al., 2014). These residues may occupy BamA's lateral pore, ultimately locking its function. LlpA's rigid nature and the targeting of an essential protein strongly advocate a killing-upon-contact mechanism, in contrast to the killing-following-uptake of the more flexible S-type pyocins; the latter need partial unfolding to penetrate target cells via the $\beta$-barrel of TonB-dependent transporters and deliver their toxin load (White et al., 2017). A second unanswered issue concerns the observation that some (mainly fluorescent) pseudomonads are killed by different LlpAs (Ghequire et al., 2012a). Interestingly, a second $\operatorname{bam} A$ can be retrieved in the genomes of some pseudomonads, often (but not exclusively) belonging to the P. fluorescens group (Heinz and Lithgow, 2014). The physiological role of this BamA paralog remains undisclosed. The presence of a different L6 sequence type in this second BamA may explain the susceptibility of some pseudomonads to different LlpAs, though this is subject to experimental verification.

\section{LIPA: A PROMISING PROTEIN ANTIBIOTIC FOR BACTERIOCIN COCKTAILS?}

Their high potency, biodegradability and selective action makes bacteriocins a promising drug lead (Behrens et al., 2017; Ghequire and De Mot, 2018). Envisaging their therapeutic use, several mid-sized pyocins - including lectin-like bacteriocins - have been tested in a murine model of acute lung infection, and their high efficacy was demonstrated (McCaughey et al., 2016b). Interestingly, lectin-like pyocins are also amenable to largescale production in plants (Paškevičius et al., 2017). The narrow spectrum of activity of bacteriocins nevertheless requires that several of these protein antibiotics are combined in a cocktail to guarantee coverage of the species diversity (Behrens et al., 2017). At this point it remains to be assessed (i) whether L-type pyocins could constitute a stable ingredient for such a cocktail, and (ii) whether the (low) mutation rate of L6 in BamA resulting in bacteriocin resistance (Ghequire et al., 2018 b) is physiologically relevant, and whether this has any effect on bacterial fitness. Given the essential role of the BAM complex, several other therapeutic strategies are currently explored to interfere with its function, such as via monoclonal antibodies (Storek et al., 2018), peptides (Mori et al., 2012; Hagan et al., 2015) or peptidomimetic antibiotics (Urfer et al., 2016).

\section{PATCHY DISTRIBUTION OF LECTIN-LIKE BACTERIOCIN GENES}

Lectin-like bacteriocin genes can be retrieved in genomes of virtually all Pseudomonas species, although sequence identity between LlpA homologs may be as low as 23\% (pairwise AA identity among LlpAs), even if they originate from the same species (Supplementary Figure S2). The sole notable exception is $P$. aeruginosa in which $\mathrm{L}$ pyocins display high sequence similarity. Pyocins L1 and L2 share $86 \%$ amino acid sequence identity but exhibit a different target spectrum, coupled to the targeting of different BamA subsets (see above). Homology searches reveal the occurrence of a putative pyocin L4 in a small set of $P$. aeruginosa strains (e.g., in $P$. aeruginosa env100) that resembles pyocins L1 and L2 well (82 and 91\% AA sequence identity, respectively). Possibly, pyocin L4 targets yet another L6 sequence type of BamA. On the contrary, pyocin L3 is much more diverged ( $\sim 26 \%$ sequence identity to L1/L2/L4). Overall, L pyocins can be retrieved in $\sim 4 \%$ of the assembled $P$. aeruginosa genomes, and a similar percentage ( $\sim 5 \%)$ of strains from other Pseudomonas species carry an $l l p A$ bacteriocin gene in their genome. LlpAs appear to occur more frequently in plant-associated and soil-dwelling pseudomonads, which may reflect a possible ancestral relationship with MMBL lectins from monocot plants. With few exceptions, Pseudomonas isolates only host one L-type bacteriocin gene in their genome, if any (Ghequire and De Mot, 2014). The latter observation strongly contrasts with modular S-type bacteriocins for which usually multiple representatives, albeit with different receptorbinding/toxin domain combinations, are present within a single Pseudomonas genome (Loper et al., 2012; Ghequire and De Mot, 2014; Sharp et al., 2017; Beaton et al., 2018). Bacteriocin sequences from strains encoding two LlpAs are usually dissimilar (30-52\% pairwise AA id), arguing against a duplication event.

Genes encoding (putative) L-type bacteriocins have been recruited to a variety of loci, but are often present in tailocin and prophage clusters (Ghequire et al., 2015; Wang et al., 2016). As cargo genes, these $l l p A$ genes may spread via horizontal gene transfer. Lectin-like bacteriocin genes are hallmarked by a lower than host-average $\mathrm{G}+\mathrm{C}$ content, a feature they share with modular bacteriocins (Mavrodi et al., 2009; Loper et al., 2012; Dingemans et al., 2016; Ghequire et al., 2017a,b; Ghequire and Öztürk, 2018). In general no clear correlation between LlpA phylogeny and Pseudomonas taxonomy can be made (except for $P$. aeruginosa, Supplementary Figure S2). Together with the observation that LlpA action may surpass species boundaries (Ghequire et al., 2012a), this further complicates the introduction of a thoughtful (re)classification of L-type bacteriocins. This lack of phylogeny-taxonomy correlation is reflected in the spectrum of BamA L6 variants that is not confined to species boundaries.

In addition to Pseudomonas, LlpA-like bacteriocins have also been described in another $\gamma$-proteobacterial genus, Xanthomonas (Ghequire et al., 2012a) and in the $\beta$-proteobacterium Burkholderia (Ghequire et al., 2013a; Rojas-Rojas et al., 2018) (Table 1), and putative L-type bacteriocins can also be detected in (select) genomes of a number of other genera, such as Chromobacterium and Caballeronia (both $\beta$-proteobacteria), 
though it remains unclear whether these proteins are bactericidal molecules as well. It also remains to be investigated whether LPS and BamA equally serve as receptors in susceptible strains of Xanthomonas and Burkholderia. D-rhamnose was previously detected as a constituent in lipopolysaccharides of Xanthomonas (Molinaro et al., 2003) and Burkholderia (VinionDubiel and Goldberg, 2003; Karapetyan et al., 2006), although sugar-binding affinity for another oligosaccharide cannot be excluded a priori. Also in genomes of $\delta$-proteobacteria (such as Chondromyces), Bacteroidetes (Chryseobacterium, Spirosoma, etc.) and diverse actinobacteria (Arthrobacter, Pseudonocardia, etc.), genes encoding a tandem MMBL protein can be retrieved. Furthermore, MMBL domains are often fused to one or more distinct domains, as highlighted earlier (Ghequire et al., 2012b). Overall, lectin-like bacteriocins seem confined to rather limited bacterial genera, thus representing a highly specialized tool, particularly apt for interbacterial warfare in plant-associated niches.

\section{LIpB: A MINIMIZED LECTIN-LIKE BACTERIOCIN?}

In Pseudomonas genomes, a second type of B-lectin proteins can be discerned (Ghequire et al., 2012b) (Supplementary Table S1). These proteins, tentatively termed LlpBs, only host a single lectin domain, equally followed by a carboxy-terminal extension as is the case for LlpAs (size of $\sim 166$ AA for LlpBs vs. $\sim 278$ AA for LlpAs). The lectin domains of most of these LlpBs cluster on a distinct branch associated with the LlpA amino-terminal domain clade (Figure 2 and Supplementary Figure S1). Characteristic to B-lectins, these LlpBs consistently host a tryptophan triad and three potential sugar-binding motifs, one of which is well conserved and may be involved in carbohydrate binding. Antagonistic tests with select recombinant LlpB demonstrate that these proteins indeed display bactericidal action (Ghequire, 2013). Possibly the LPS-binding and targetselective function of LlpBs are condensed in a single lectin domain. One question arising is whether $l p A$ genes evolved from $l l p B$ genes, or vice versa, or whether $l l p A$ and $l l p B$ genes were acquired independently. Overall, $l_{p} B$ genes can be retrieved in a variety of Pseudomonas species, but they appear to be absent from $P$. aeruginosa genomes. Similar to $l l p A$ genes, $l l p B$ genes are also present as cargos in tailocin or prophage clusters, for example in Pseudomonas libanensis DSM 17149 and P. fluorescens FF9, respectively, although this coupling appears to be much rarer.

\section{SECRETION WITH A SACRIFICE?}

With the exception of a small subset of L-type pyocins (pyocin L3 and highly similar sequences) and Burkholderia/Xanthomonas representatives (Ghequire et al., 2014), LlpAs are not preceded by a Sec-dependent signal sequence motif to facilitate their secretion from producer cells. The same is true for S-type modular bacteriocins in Pseudomonas (Ghequire and De Mot,
2014), raising the question how these proteins can be released from producer cells? Group A colicin genes - encoding modular bacteriocins from Escherichia coli - are joined by a lysis module, typically located downstream of the bacteriocin gene, and these lipoprotein-encoding genes are co-expressed along with the colicins. For group B colicins, as is the case for Pseudomonas bacteriocins, a lysis gene is lacking (Cascales et al., 2007). However, for these colicins in particular it was found that the cellular release may be mediated by a prophage lysis module encoded elsewhere in the genome (Nedialkova et al., 2016; van Raay and Kerr, 2016). Conceivably, a similar strategy may be followed by LlpAs and other Pseudomonas bacteriocins as well, although this remains to be explored. The observation that L-type and other bacteriocin genes can often be retrieved within or in close proximity of tailocin and prophage gene clusters may facilitate co-expression of bacteriocin genes and lysis modules and co-inheritance, suggestive of such lysis "piggybacking" (Mavrodi et al., 2009; Loper et al., 2012; Ghequire et al., 2015, 2018a; Wang et al., 2016). Regardless of the mechanism used, the expression of lysis genes poses a burden on producer cells. For this reason, it is expected that only part of a Pseudomonas cell population secretes lectin-like bacteriocins, as demonstrated in $E$. coli for a colicin A/E2/E7 competition model (Bayramoglu et al., 2017).

\section{STRESS-TRIGGERED RETALIATION?}

The environmental cues controlling expression of L-type bacteriocins remain poorly understood to date. For LlpA from P. mosselii BW11M1 (Parret et al., 2003), and LlpA1 $1_{\mathrm{Pf}-5}$ and LlpA2 ${ }_{\mathrm{Pf}-5}$ from $P$. protegens $\mathrm{Pf}-5$ (Parret et al., 2005), constitutive expression was observed, though it should be emphasized that bacteriocin-expression conditions may vary from strain to strain. Following exposure to UV light, LlpA $A_{\mathrm{BW} 11 \mathrm{M} 1}$ expression is significantly enhanced. Similar observations have been made for several other (Pseudomonas) bacteriocins as well (Ghazaryan et al., 2014; Godino et al., 2015; Hockett and Baltrus, 2017; Turano et al., 2017), and such DNA-damaging conditions (e.g., via mitomycin $\mathrm{C}$ treatments) constitute a common strategy to induce bacteriocin overproduction. Screening of a $P$. mosselii BW11M1 transposon mutant library revealed that LlpA expression is reduced in a $\operatorname{rec} A$ and spoT mutant background, confirming the UV-light-induced expression of LlpA (de los Santos et al., 2005). Following DNA-damaging treatment, RecA is activated leading to a stress response, which includes the activation of S-type pyocin expression in P. aeruginosa (Michel-Briand and Baysse, 2002; Ghequire and De Mot, 2014). Therefore, L-type bacteriocin expression may depend (in part) on a general regulatory mechanism triggering bacteriocin expression in pseudomonads. Similarly, colicins also depend on a SOS system to initiate their expression, mediated by LexA. This protein controls two overlapping SOS boxes, which prevents untimely colicin expression and cell lysis (Gillor et al., 2008; Žgur-Bertok, 2012; Fornelos et al., 2016). 


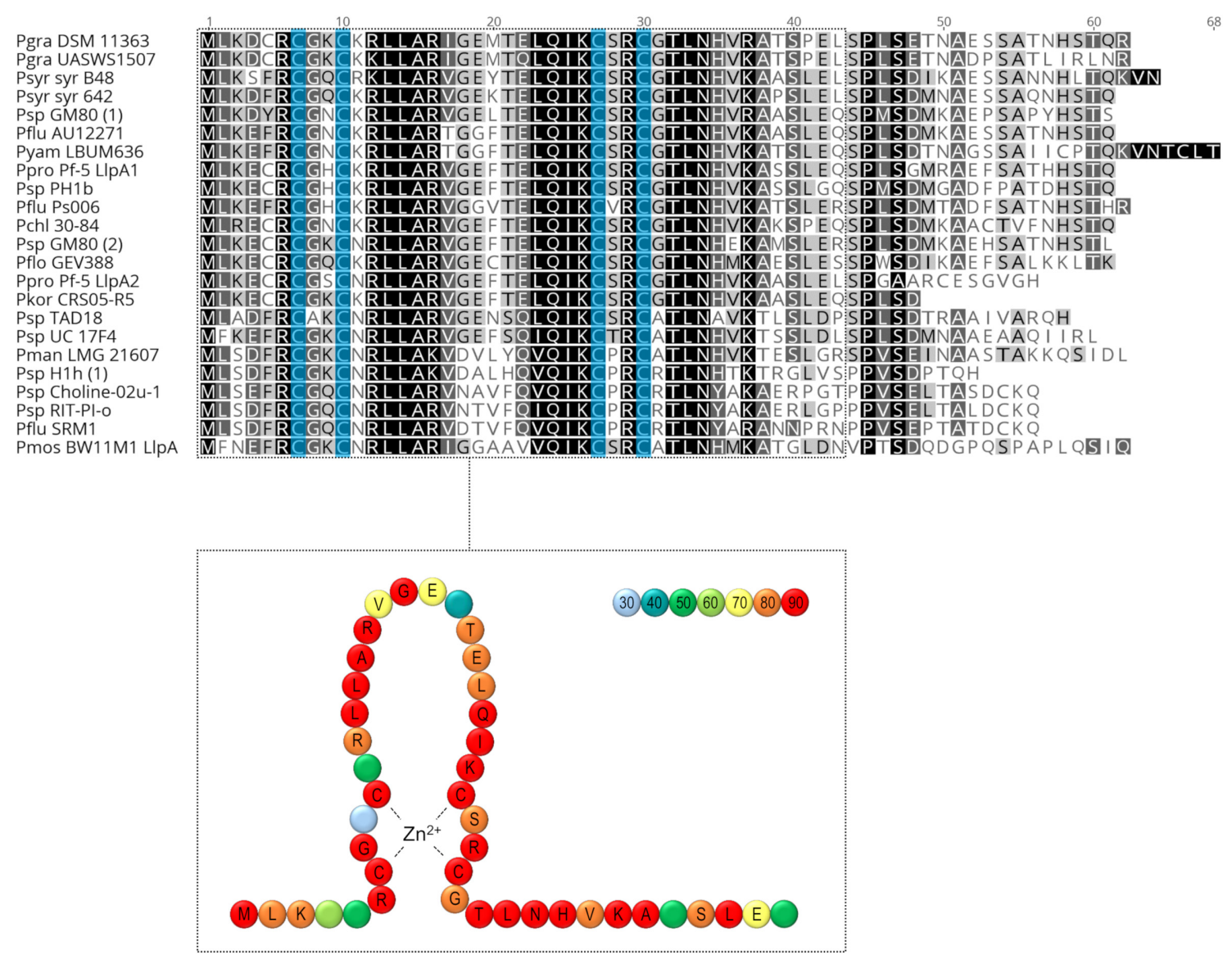

FIGURE 4 | Multiple sequence alignment of Pseudomonas Com proteins (<90\% pairwise AA sequence identity), encoded by genes preceding IIpA genes. Differential shading reflects the sequence conservation. The conserved zinc-coordinating cysteine residues are highlighted in blue. In case two $L$ lpAs are present in a single strain, preceding Com proteins (if present) are specified with (1) and (2). The zinc-finger domains (PF10122) of these Com proteins are marked by a dotted box and a schematic representation of the sequence conservation within this domain is shown under the alignment. Amino acids are depicted by beads and colored according to the (weighted) degree (\%) of sequence conservation (legend) (AA sequences of all llpA-preceding Com proteins were included). In case sequence conservation is $70 \%$ or higher, the corresponding amino acid is identified inside the dot. The backbone of the scheme corresponds to the Com protein of the phage Mu. Pchl, Pseudomonas chlororaphis; Pflo, Pseudomonas floridensis; Pflu, Pseudomonas fluorescens; Pgra, Pseudomonas graminis; Pkor, Pseudomonas koreensis; Pman, Pseudomonas mandelii; Pmos, Pseudomonas mosselii; Ppro, Pseudomonas protegens; Psp, Pseudomonas sp.; Psyr syr, Pseudomonas syringae pv. syringae; Pyam, Pseudomonas yamanorum.

With the exception of $P$. aeruginosa, a large majority of L-type bacteriocin genes $(\sim 90 \%)$ are preceded by a short gene encoding a putative zinc-finger-like protein (PF10122) (Ghequire et al., 2015), which is often not annotated in Pseudomonas genomes. Hallmarked by four conserved cysteine residues, this $\sim 60$-AA protein is homologous to Com, a translational activator protein of bacteriophage $\mathrm{Mu}$ that initiates expression of the mom operon (Hattman et al., 1991; Witkowski et al., 1995). The amino-terminal region, which includes the coordinating cysteine residues, is largely conserved, whereas the Com tail may vary significantly in length (Figure 4). An interesting observation is that non-L-type bacteriocin genes present as tailocin cargos in pseudomonads may equally be preceded by such a com-like gene (Ghequire et al., 2015). Furthermore, in some strains that is also the case for the lytic enzyme that is part of the tailocin lysis cassette. Com-linked genes also appear in other Pseudomonas contexts, for instance, in
P. syringae this gene is (often) linked to glycosyl hydrolase genes, including levansucrase homologs (Srivastava et al., 2012). The more general (regulatory) role of this Com protein remains to be explored.

\section{CONCLUDING REMARKS}

Following the identification of the first lectin-like bacteriocin with a tandem lectin module architecture in a $P$. mosselii isolate, multiple LlpA representatives have been studied in a variety Pseudomonas species and other genera, largely facilitated by an ongoing release of genome sequencing data. The structure of LlpA, and the subsequent identification of CPA and BamA in particular as target receptors, are indicative of a novel killing mechanism that does not require protein import as observed for modular S-type bacteriocins. Undoubtedly a careful 
assessment of the interaction between LlpA and BamA will shed further light on the interference process exerted by these bacteriocins. Future research also needs to clarify the regulatory features for expression of this unusual group of bacteriocins, and elucidate how their secretion is accomplished. Given that the B-lectin module is present in proteins with different domain organizations, other lectin-like bacteriocin types likely exist.

\section{AUTHOR CONTRIBUTIONS}

MG, BÖ, and RDM wrote the manuscript. All authors revised and approved the manuscript.

\section{REFERENCES}

Aoki, S. K., Malinverni, J. C., Jacoby, K., Thomas, B., Pamma, R., Trinh, B. N., et al. (2008). Contact-dependent growth inhibition requires the essential outer membrane protein BamA (YaeT) as the receptor and the inner membrane transport protein AcrB. Mol. Microbiol. 70, 323-340. doi: 10.1111/j.1365-2958. 2008.06404.x

Arasu, A., Kumaresan, V., Palanisamy, R., Arasu, M. V., Al-Dhabi, N. A., Ganesh, M. R., et al. (2017). Bacterial membrane binding and pore formation abilities of carbohydrate recognition domain of fish lectin. Dev. Comp. Immunol. 67, 202-212. doi: 10.1016/j.dci.2016.10.001

Azevedo, A. C., Bento, C. B., Ruiz, J. C., Queiroz, M. V., and Mantovani, H. C. (2015). Distribution and genetic diversity of bacteriocin gene clusters in rumen microbial genomes. Appl. Environ. Microbiol. 81, 7290-7304. doi: 10.1128/ AEM.01223-15

Barre, A., Van Damme, E. J., Peumans, W. J., and Rougé, P. (1999). Homology modelling of the core domain of the endogenous lectin comitin: structural basis for its mannose-binding specificity. Plant Mol. Biol. 39, 969-978. doi: 10.1023/A:1006133527621

Barreteau, H., Bouhss, A., Fourgeaud, M., Mainardi, J. L., Touzé, T., Gérard, F., et al. (2009). Human- and plant-pathogenic Pseudomonas species produce bacteriocins exhibiting colicin M-like hydrolase activity towards peptidoglycan precursors. J. Bacteriol. 191, 3657-3664. doi: 10.1128/JB.01824-08

Bayramoglu, B., Toubiana, D., van Vliet, S., Inglis, R. F., Shnerb, N., and Gillor, O. (2017). Bet-hedging in bacteriocin producing Escherichia coli populations: the single cell perspective. Sci. Rep. 7:42068. doi: 10.1038/srep42068

Beaton, A., Lood, C., Cunningham-Oakes, E., MacFadyen, A., Mullins, A. J., Bestawy, W. E., et al. (2018). Community-led comparative genomic and phenotypic analysis of the aquaculture pathogen Pseudomonas baetica a390T sequenced by Ion semiconductor and Nanopore technologies. FEMS Microbiol. Lett. 365:fny069. doi: 10.1093/femsle/fny069

Behrens, H. M., Six, A., Walker, D., and Kleanthous, C. (2017). The therapeutic potential of bacteriocins as protein antibiotics. Emerg. Top. Life Sci. 1, 65-74. doi: 10.1042/ETLS20160016

Buth, S. A., Shneider, M. M., Scholl, D., and Leiman, P. G. (2018). Structure and analysis of R1 and R2 pyocin receptor-binding fibers. Viruses 10:E427. doi: 10.3390/v10080427

Cascales, E., Buchanan, S. K., Duché, D., Kleanthous, C., Lloubès, R., Postle, K., et al. (2007). Colicin biology. Microbiol. Mol. Biol. Rev. 71, 158-229. doi: 10. 1128/MMBR.00036-06

Chassaing, B., and Cascales, E. (2018). Antibacterial weapons: targeted destruction in the microbiota. Trends Microbiol. 26, 329-338. doi: 10.1016/j.tim.2018.01.006

Chen, J., Stevenson, D. M., and Weimer, P. J. (2004). Albusin B, a bacteriocin from the ruminal bacterium Ruminococcus albus 7 that inhibits growth of Ruminococcus flavefaciens. Appl. Environ. Microbiol. 70, 3167-3170. doi: 10. 1128/AEM.70.5.3167-3170.2004

de los Santos, P. E., Parret, A. H., and De Mot, R. (2005). Stress-related Pseudomonas genes involved in production of bacteriocin LlpA. FEMS Microbiol. Lett. 244, 243-250. doi: 10.1016/j.femsle.2005.01.049

\section{FUNDING}

MG is a postdoctoral fellow from FWO Vlaanderen (12M4618N). This work was supported by the FWO Vlaanderen under Grants $1523116 \mathrm{~N}, 1525618 \mathrm{~N}$, and $1529718 \mathrm{~N}$ (to MG). The funders had no role in study design, data collection and interpretation, or the decision to submit the work for publication.

\section{SUPPLEMENTARY MATERIAL}

The Supplementary Material for this article can be found online at: https://www.frontiersin.org/articles/10.3389/fmicb. 2018.02706/full\#supplementary-material

de Santana Evangelista, K., Andrich, F., Figueiredo de Rezende, F., Niland, S., Cordeiro, M. N., Horlacher, T., et al. (2009). Plumieribetin, a fish lectin homologous to mannose-binding B-type lectins, inhibits the collagen-binding alphalbetal integrin. J. Biol. Chem. 284, 34747-34759. doi: 10.1074/jbc.M109. 002873

Dingemans, J., Ghequire, M. G., Craggs, M., De Mot, R., and Cornelis, P. (2016). Identification and functional analysis of a bacteriocin, pyocin S6, with ribonuclease activity from a Pseudomonas aeruginosa cystic fibrosis clinical isolate. Microbiologyopen 5, 413-423. doi: 10.1002/mbo3.339

Doerner, P. A., and Sousa, M. C. (2017). Extreme dynamics in the BamA $\beta$-Barrel seam. Biochemistry 56, 3142-3149. doi: 10.1021/acs.biochem.7b00281

Dorosky, R. J., Yu, J. M., Pierson, L. S. III, and Pierson, E. A. (2017). Pseudomonas chlororaphis produces two distinct R-tailocins that contribute to bacterial competition in biofilms and on roots. Appl. Environ. Microbiol. 83:e00706-17. doi: 10.1128/AEM.00706-17

Falchi, F. A., Maccagni, E. A., Puccio, S., Peano, C., De Castro, C., Palmigiano, A., et al. (2018). Mutation and suppressor analysis of the essential lipopolysaccharide transport protein LptA reveals strategies to overcome severe outer membrane permeability defects in Escherichia coli. J. Bacteriol. 200:e00487-17. doi: 10.1128/JB.00487-17

Fischer, S., Godino, A., Quesada, J. M., Cordero, P., Jofré, E., Mori, G., et al. (2012). Characterization of a phage-like pyocin from the plant growth-promoting rhizobacterium Pseudomonas fluorescens SF4c. Microbiology 158, 1493-1503. doi: 10.1099/mic.0.056002-0

Fornelos, N., Browning, D. F., and Butala, M. (2016). The use and abuse of LexA by mobile genetic elements. Trends Microbiol. 24, 391-401. doi: 10.1016/j.tim. 2016.02.009

Fouquaert, E., Peumans, W. J., Gheysen, G., and Van Damme, E. J. (2011). Identical homologs of the Galanthus nivalis agglutinin in Zea mays and Fusarium verticillioides. Plant Physiol. Biochem. 49, 46-54. doi: 10.1016/j.plaphy.2010.09. 018

Gao, Z. M., Zheng, B., Wang, W. Y., Li, Q., and Yuan, Q. P. (2011). Cloning and functional characterization of a GNA-like lectin from Chinese Narcissus (Narcissus tazetta var. Chinensis Roem). Physiol. Plant 142, 193-204. doi: 10. 1111/j.1399-3054.2011.01449.x

Ghazaryan, L., Tonoyan, L., Ashhab, A. A., Soares, M. I., and Gillor, O. (2014). The role of stress in colicin regulation. Arch. Microbiol. 196, 753-764. doi: 10.1007/s00203-014-1017-8

Ghequire, M. (2013). Protein-mediated killing among bacteria: structure and function of prokaryotic MMBL lectins. Ph.D. thesis, University of Leuven, Leuven, 127.

Ghequire, M. G., and De Mot, R. (2014). Ribosomally encoded antibacterial proteins and peptides from Pseudomonas. FEMS Microbiol. Rev. 38, 523-568. doi: 10.1111/1574-6976.12079

Ghequire, M. G., and De Mot, R. (2015). The tailocin tale: peeling off phage tails. Trends Microbiol. 23, 587-590. doi: 10.1016/j.tim.2015.07.011

Ghequire, M. G., De Canck, E., Wattiau, P., Van Winge, I., Loris, R., Coenye, T., et al. (2013a). Antibacterial activity of a lectin-like Burkholderia cenocepacia protein. Microbiologyopen 2, 566-575. doi: 10.1002/mbo3.95 
Ghequire, M. G., Dillen, Y., Lambrichts, I., Proost, P., Wattiez, R., and De Mot, R. (2015). Different ancestries of R tailocins in rhizospheric Pseudomonas isolates. Genome Biol. Evol. 7, 2810-2828. doi: 10.1093/gbe/evv184

Ghequire, M. G., Dingemans, J., Pirnay, J. P., De Vos, D., Cornelis, P., and De Mot, R. (2014). O serotype-independent susceptibility of Pseudomonas aeruginosa to lectin-like pyocins. Microbiologyopen 3, 875-884. doi: 10.1002/ mbo3.210

Ghequire, M. G., Garcia-Pino, A., Lebbe, E. K., Spaepen, S., Loris, R., and De Mot, R. (2013b). Structural determinants for activity and specificity of the bacterial toxin LlpA. PLoS Pathog. 9:e1003199. doi: 10.1371/journal.ppat. 1003199

Ghequire, M. G., Kemland, L., Anoz-Carbonell, E., Buchanan, S. K., and De Mot, R. (2017a). A natural chimeric Pseudomonas bacteriocin with novel pore-forming activity parasitizes the ferrichrome transporter. mBio 8:e01961-16. doi: 10.1128/ mBio.01961-16

Ghequire, M. G., Kemland, L., and De Mot, R. (2017b). Novel immunity proteins associated with colicin M-like bacteriocins exhibit promiscuous protection in Pseudomonas. Front. Microbiol. 8:93. doi: 10.3389/fmicb.2017. 00093

Ghequire, M. G., Li, W., Proost, P., Loris, R., and De Mot, R. (2012a). Plant lectin-like antibacterial proteins from phytopathogens Pseudomonas syringae and Xanthomonas citri. Environ. Microbiol. Rep. 4, 373-380. doi: 10.1111/j. 1758-2229.2012.00331.x

Ghequire, M. G., Loris, R., and De Mot, R. (2012b). MMBL proteins: from lectin to bacteriocin. Biochem. Soc. Trans. 40, 1553-1559. doi: 10.1042/BST20 120170

Ghequire, M. G., Swings, T., Michiels, J., Gross, H., and De Mot, R. (2016). Draft genome sequence of Pseudomonas putida BW11M1, a banana rhizosphere isolate with a diversified antimicrobial armamentarium. Genome Announc. 4:e00251-16. doi: 10.1128/genomeA.00251-16

Ghequire, M. G. K., Buchanan, S. K., and De Mot, R. (2018a). The ColM Family, polymorphic toxins breaching the bacterial cell wall. mBio 9:e02267-17. doi: 10.1128/mBio.02267-17

Ghequire, M. G. K., and De Mot, R. (2018). Turning over a new leaf: bacteriocins going green. Trends Microbiol. 26, 1-2. doi: 10.1016/j.tim.2017. 11.001

Ghequire, M. G. K., and Öztürk, B. (2018). A colicin M-type bacteriocin from Pseudomonas aeruginosa targeting the $\mathrm{HxuC}$ heme receptor requires a novel immunity partner. Appl. Environ. Microbiol. 84:e00716-18. doi: 10.1128/AEM. 00716-18

Ghequire, M. G. K., Swings, T., Michiels, J., Buchanan, S., and De Mot, R. (2018b). Hitting with a BAM: selective killing by lectin-like bacteriocins. mBio 9:e02138-17. doi: 10.1128/mBio.02138-17

Ghoul, M., West, S. A., Johansen, H. K., Molin, S., Harrison, O. B., Maiden, M. C., et al. (2015). Bacteriocin-mediated competition in cystic fibrosis lung infections. Proc. Biol. Sci. 282:1814. doi: 10.1098/rpsb.2015.0972

Gillor, O., Vriezen, J. A., and Riley, M. A. (2008). The role of SOS boxes in enteric bacteriocin regulation. Microbiology 154, 1783-1792. doi: 10.1099/mic.0.2007/ 016139-0

Godino, A., Príncipe, A., and Fischer, S. (2015). A ptsP deficiency in PGPR Pseudomonas fluorescens SF39a affects bacteriocin production and bacterial fitness in the wheat rhizosphere. Res. Microbiol. 167, 178-189. doi: 10.1016/j. resmic.2015.12.003

Hagan, C. L., Wzorek, J. S., and Kahne, D. (2015). Inhibition of the $\beta$-barrel assembly machine by a peptide that binds BamD. Proc. Natl. Acad. Sci. U.S.A. 112, 2011-2016. doi: 10.1073/pnas.1415955112

Hattman, S., Newman, L., Murthy, H. M., and Nagaraja, V. (1991). Com, the phage $\mathrm{Mu}$ mom translational activator, is a zinc-binding protein that binds specifically to its cognate mRNA. Proc. Natl. Acad. Sci. U.S.A. 88, 10027-10031. doi: $10.1073 /$ pnas.88.22.10027

Heinz, E., and Lithgow, T. (2014). A comprehensive analysis of the Omp85/TpsB protein superfamily structural diversity, taxonomic occurrence, and evolution. Front. Microbiol. 5:370. doi: 10.3389/fmicb.2014. 00370

Hockett, K. L., and Baltrus, D. A. (2017). Use of the soft-agar overlay technique to screen for bacterially produced inhibitory compounds. J. Vis. Exp. 119:e55064. doi: 10.3791/55064
Hockett, K. L., Clark, M., Scott, S., and Baltrus, D. A. (2017). Conditionally redundant bacteriocin targeting by Pseudomonas syringae. bioRxiv [Preprint]. doi: $10.1101 / 167593$

Hockett, K. L., Renner, T., and Baltrus, D. A. (2015). Independent co-option of a tailed bacteriophage into a killing complex in Pseudomonas. mBio 6:e00452. doi: 10.1128/mBio.00452-15

Inglis, R. F., West, S., and Buckling, A. (2014). An experimental study of strong reciprocity in bacteria. Biol. Lett. 10:20131069. doi: 10.1098/rsbl.2013.1069

Jamet, A., and Nassif, X. (2015). New Players in the toxin field: polymorphic toxin systems in bacteria. mBio 6:e00285-15. doi: 10.1128/mBio.00285-15

Joshi, A., Grinter, R., Josts, I., Chen, S., Wojdyla, J. A., Lowe, E. D., et al. (2015). Structures of the ultra-high-affinity protein-protein complexes of pyocins S2 and AP41 and their cognate immunity proteins from Pseudomonas aeruginosa. J. Mol. Biol. 427, 2852-2866. doi: 10.1016/j.jmb.2015.07.014

Karapetyan, G., Kaczynski, Z., Iacobellis, N. S., Evidente, A., and Holst, O. (2006). The structure of the O-specific polysaccharide of the lipopolysaccharide from Burkholderia gladioli pv. agaricicola. Carbohydr. Res. 341, 930-934. doi: 10. 1016/j.carres.2006.02.010

Kocincová, D., and Lam, J. S. (2013). A deletion in the wapB promoter in many serotypes of Pseudomonas aeruginosa accounts for the lack of a terminal glucose residue in the core oligosaccharide and resistance to killing by R3-pyocin. Mol. Microbiol. 89, 464-478. doi: 10.1111/mmi. 12289

Köhler, T., Donner, V., and van Delden, C. (2010). Lipopolysaccharide as shield and receptor for R-pyocin-mediated killing in Pseudomonas aeruginosa. J. Bacteriol. 192, 1921-1928. doi: 10.1128/JB.01459-09

Lam, J. S., Taylor, V. L., Islam, S. T., Hao, Y., and Kocíncová, D. (2011). Genetic and functional diversity of Pseudomonas aeruginosa lipopolysaccharide. Front. Microbiol. 2:118. doi: 10.3389/fmicb.2011.00118

Lavermicocca, P., Lonigro, S. L., Valerio, F., Evidente, A., and Visconti, A. (2002). Reduction of olive knot disease by a bacteriocin from Pseudomonas syringae pv. ciccaronei. Appl. Environ. Microbiol. 68, 1403-1407. doi: 10.1128/AEM.68. 3.1403-1407.2002

Leyton, D. L., Belousoff, M. J., and Lithgow, T. (2015). The $\beta$-barrel assembly machinery complex. Methods Mol. Biol. 1329, 1-16. doi: 10.1007/978-1-49392871-2_1

Loper, J. E., Hassan, K. A., Mavrodi, D. V., Davis, E. W. II, Lim, C. K., Shaffer, B. T., et al. (2012). Comparative genomics of plant-associated Pseudomonas spp.: insights into diversity and inheritance of traits involved in multitrophic interactions. PLoS Genet. 8:e1002784. doi: 10.1371/journal.pgen.1002784

Mavrodi, D. V., Loper, J. E., Paulsen, I. T., and Thomashow, L. S. (2009). Mobile genetic elements in the genome of the beneficial rhizobacterium Pseudomonas fluorescens Pf-5. BMC Microbiol. 9:8. doi: 10.1186/1471-2180-9-8

McCaughey, L. C., Grinter, R., Josts, I., Roszak, A. W., Waløen, K. I., Cogdell, R. J., et al. (2014). Lectin-like bacteriocins from Pseudomonas spp. utilise D-rhamnose containing lipopolysaccharide as a cellular receptor. PLoS Pathog. 10:e1003898. doi: 10.1371/journal.ppat.1003898

McCaughey, L. C., Josts, I., Grinter, R., White, P., Byron, O., Tucker, N. P., et al. (2016a). Discovery, characterisation and in vivo activity of pyocin SD2, a protein antibiotic from Pseudomonas aeruginosa. Biochem. J. 473, 2345-2358. doi: 10.1042/BCJ20160470

McCaughey, L. C., Ritchie, N. D., Douce, G. R., Evans, T. J., and Walker, D. (2016b). Efficacy of species-specific protein antibiotics in a murine model of acute Pseudomonas aeruginosa lung infection. Sci. Rep. 6:30201. doi: 10.1038/ srep30201

Metelev, M., Serebryakova, M., Ghilarov, D., Zhao, Y., and Severinov, K. (2013). Structure of microcin B-like compounds produced by Pseudomonas syringae and species specificity of their antibacterial action. J. Bacteriol. 195, 4129-4137. doi: 10.1128/JB.00665-13

Michel-Briand, Y., and Baysse, C. (2002). The pyocins of Pseudomonas aeruginosa. Biochimie 84, 499-510. doi: 10.1016/S0300-9084(02)01422-0

Molinaro, A., Silipo, A., Lanzetta, R., Newman, M. A., Dow, J. M., and Parrilli, M. (2003). Structural elucidation of the O-chain of the lipopolysaccharide from Xanthomonas campestris strain 8004. Carbohydr. Res. 338, 277-281. doi: 10. 1016/S0008-6215(02)00433-0

Mori, N., Ishii, Y., Tateda, K., Kimura, S., Kouyama, Y., Inoko, H., et al. (2012). A peptide based on homologous sequences of the $\beta$-barrel assembly machinery 
component BamD potentiates antibiotic susceptibility of Pseudomonas aeruginosa. J. Antimicrob. Chemother. 67, 2173-2181. doi: 10.1093/jac/dks174

Nedialkova, L. P., Sidstedt, M., Koeppel, M. B., Spriewald, S., Ring, D., Gerlach, R. G., et al. (2016). Temperate phages promote colicin-dependent fitness of Salmonella enterica serovar Typhimurium. Environ. Microbiol. 18, 1591-1603. doi: 10.1111/1462-2920.13077

Ni, D., Wang, Y., Yang, X., Zhou, H., Hou, X., Cao, B., et al. (2014). Structural and functional analysis of the $\beta$-barrel domain of BamA from Escherichia coli. FASEB J. 28, 2677-2685. doi: 10.1096/fj.13-248450

Noinaj, N., Gumbart, J. C., and Buchanan, S. K. (2017). The $\beta$-barrel assembly machinery in motion. Nat. Rev. Microbiol. 15, 197-204. doi: 10.1038/nrmicro. 2016.191

Noinaj, N., Kuszak, A. J., Balusek, C., Gumbart, J. C., and Buchanan, S. K. (2014). Lateral opening and exit pore formation are required for BamA function. Structure 22, 1055-1062. doi: 10.1016/j.str.2014.05.008

Pang, Y. Z., Shen, G. A., Liao, Z. H., Yao, J. H., Fei, J., Sun, X. F., et al. (2003). Molecular cloning and characterization of a novel lectin gene from Zephyranthes candida. DNA Seq. 14, 163-167. doi: 10.1080/ 1042517031000089450

Park, H. J., Jeong, J. M., Bae, J. S., Kim, J. W., An, C. M., Min, B. H., et al. (2016). Molecular cloning and expression analysis of a new lily-type lectin in the rock bream, Oplegnathus fasciatus. Dev. Comp. Immunol. 65, 25-30. doi: 10.1016/j.dci.2016.06.014

Parret, A. H., Schoofs, G., Proost, P., and De Mot, R. (2003). Plant lectin-like bacteriocin from a rhizosphere-colonizing Pseudomonas isolate. J. Bacteriol. 185, 897-908. doi: 10.1128/JB.185.3.897-908.2003

Parret, A. H., Temmerman, K., and De Mot, R. (2005). Novel lectin-like bacteriocins of biocontrol strain Pseudomonas fluorescens Pf-5. Appl. Environ. Microbiol. 71, 5197-5207. doi: 10.1128/AEM.71.9.5197-5207.2005

Paškevičius, S., Starkevič, U., Misiūnas, A., Vitkauskiené, A., Gleba, Y., and Ražanskienè, A. (2017). Plant-expressed pyocins for control of Pseudomonas aeruginosa. PLoS One 12:e0185782. doi: 10.1371/journal.pone.0185782

Pereira, P. R., Winter, H. C., Vericimo, M. A., Meagher, J. L., Stuckey, J. A., Goldstein, I. J., et al. (2015). Structural analysis and binding properties of isoforms of tarin, the GNA-related lectin from Colocasia esculenta. Biochim. Biophys. Acta 1854, 20-30. doi: 10.1016/j.bbapap.2014.10.013

Príncipe, A., Fernandez, M., Torasso, M., Godino, A., and Fischer, S. (2018). Effectiveness of tailocins produced by Pseudomonas fluorescens SF4c in controlling the bacterial-spot disease in tomatoes caused by Xanthomonas vesicatoria. Microbiol. Res. 21, 94-102. doi: 10.1016/j.micres.2018.05.010

Rasouliha, B. H., Ling, H., Ho, C. L., and Chang, M. W. (2013). A predicted immunity protein confers resistance to Pyocin S5 in a sensitive strain of Pseudomonas aeruginosa. Chembiochem 14, 2444-2446. doi: 10.1002/cbic. 201300410

Rojas-Rojas, F. U., Salazar-Gómez, A., Vargas-Díaz, M. E., Vásquez-Murrieta, M. S., Hirsch, A. M., De Mot, R., et al. (2018). Broad-spectrum antimicrobial activity by Burkholderia cenocepacia TAtl-371, a strain isolated from the tomato rhizosphere. Microbiology 164, 1072-1086. doi: 10.1099/mic.0.000675

Ruhe, Z. C., Wallace, A. B., Low, D. A., and Hayes, C. S. (2013), Receptor polymorphism restricts contact-dependent growth inhibition to members of the same species. mBio 4:e00480-13. doi: $10.1128 / \mathrm{mBio}$. 00480-13

Ruiz, N., Kahne, D., and Silhavy, T. J. (2006). Advances in understanding bacterial outer-membrane biogenesis. Nat. Rev. Microbiol. 4, 57-66. doi: 10. $1038 /$ nrmicro1322

Scholl, D. (2017). Phage tail-like bacteriocins. Annu. Rev. Virol. 4, 453-467. doi: 10.1146/annurev-virology-101416-041632

Sharp, C., Bray, J., Housden, N. G., Maiden, M. C. J., and Kleanthous, C. (2017). Diversity and distribution of nuclease bacteriocins in bacterial genomes revealed using Hidden Markov Models. PLoS Comput. Biol. 13:e1005652. doi: 10.1371/journal.pcbi. 1005652

Shimokawa, M., Fukudome, A., Yamashita, R., Minami, Y., Yagi, F., Tateno, H., et al. (2012). Characterization and cloning of GNA-like lectin from the mushroom Marasmius oreades. Glycoconj. J. 29, 457-465. doi: 10.1007/s10719012-9401-6

Srivastava, A., Al-Karablieh, N., Khandekar, S., Sharmin, A., Weingart, H., and Ullrich, M. S. (2012). Genomic distribution and divergence of levansucrasecoding genes in Pseudomonas syringae. Genes 3, 115-137. doi: 10.3390/ genes3010115
Storek, K. M., Auerbach, M. R., Shi, H., Garcia, N. K., Sun, D., Nickerson, N. N., et al. (2018). Monoclonal antibody targeting the beta-barrel assembly machine of Escherichia coli is bactericidal. Proc. Natl. Acad. Sci. U.S.A. 115, 3692-3697. doi: 10.1073/pnas. 1800043115

Tsutsui, S., Tasumi, S., Suetake, H., and Suzuki, Y. (2003). Lectins homologous to those of monocotyledonous plants in the skin mucus and intestine of pufferfish, Fugu rubripes. J. Biol. Chem. 278, 20882-20889. doi: 10.1074/jbc.M301038200

Turano, H., Gomes, F., Barros-Carvalho, G. A., Lopes, R., Cerdeira, L., Netto, L. E. S., et al. (2017). Tn6350, a novel transposon carrying pyocin S8 genes encoding a bacteriocin with activity against carbapenemase-producing Pseudomonas aeruginosa. Antimicrob. Agents Chemother. 61:e00100-17. doi: 10.1128/AAC.00100-17

Urfer, M., Bogdanovic, J., Lo Monte, F., Moehle, K., Zerbe, K., Omasits, U., et al. (2016). A peptidomimetic antibiotic targets outer membrane proteins and disrupts selectively the outer membrane in Escherichia coli. J. Biol. Chem. 291, 1921-1932. doi: 10.1074/jbc.M115.691725

Van Damme, E. J., Kaku, H., Perini, F., Goldstein, I. J., Peeters, B., Yagi, F., et al. (1991). Biosynthesis, primary structure and molecular cloning of snowdrop (Galanthus nivalis L.) lectin. Eur. J. Biochem. 202, 23-30. doi: 10.1111/j.14321033.1991.tb16339.x

van Raay, K., and Kerr, B. (2016). Toxins go viral: phage-encoded lysis releases group B colicins. Environ. Microbiol. 18, 1308-1311. doi: 10.1111/1462-2920. 13246

Vinion-Dubiel, A. D., and Goldberg, J. B. (2003). Lipopolysaccharide of Burkholderia cepacia complex. J. Endotoxin Res. 9, 201-213. doi: 10.1179/ 096805103225001404

Wang, D., Yu, J. M., Dorosky, R. J., Pierson, L. S. III, and Pierson, E. A. (2016). The phenazine 2-hydroxy-phenazine-1-carboxylic acid promotes extracellular DNA release and has broad transcriptomic consequences in Pseudomonas chlororaphis 30-84. PLoS One 11:e0148003. doi: 10.1371/journal.pone.0148003

White, P., Joshi, A., Rassam, P., Housden, N. G., Kaminska, R., Goult, J. D., et al. (2017). Exploitation of an iron transporter for bacterial protein antibiotic import. Proc. Natl. Acad. Sci. U.S.A. 114, 12051-12056. doi: 10.1073/pnas. 1713741114

Wiens, M., Belikov, S. I., Kaluzhnaya, O. V., Krasko, A., Schröder, H. C., PerovicOttstadt, S., et al. (2006). Molecular control of serial module formation along the apical-basal axis in the sponge Lubomirskia baicalensis: silicateins, mannosebinding lectin and mago nashi. Dev. Genes Evol. 216, 229-242. doi: 10.1007/ s00427-005-0047-2

Willett, J. L., Ruhe, Z. C., Goulding, C. W., Low, D. A., and Hayes, C. S. (2015). Contact-dependent growth inhibition (CDI) and CdiB/CdiA twopartner secretion proteins. J. Mol. Biol. 427, 3754-3765. doi: 10.1016/j.jmb.2015. 09.010

Witkowski, R. T., Hattman, S., Newman, L., Clark, K., Tierney, D. L., PennerHahn, J., et al. (1995). The zinc coordination site of the bacteriophage $\mathrm{Mu}$ translational activator protein, com. J. Mol. Biol. 247, 753-764. doi: 10.1016/ S0022-2836(05)80153-6

Wright, L. M., Reynolds, C. D., Rizkallah, P. J., Allen, A. K., Van Damme, E. J., Donovan, M. J., et al. (2000). Structural characterisation of the native fetuinbinding protein Scilla campanulata agglutinin: a novel two-domain lectin. FEBS Lett. 468, 19-22. doi: 10.1016/S0014-5793(00)01109-1

$\mathrm{Wu}, \mathrm{L}$., and Bao, J. K. (2013). Anti-tumor and anti-viral activities of Galanthus nivalis agglutinin (GNA)-related lectins. Glycoconj. J. 30, 269-279. doi: 10.1007/ s10719-012-9440-Z

Žgur-Bertok, D. (2012). Regulating colicin synthesis to cope with stress and lethality of colicin production. Biochem. Soc. Trans. 40, 1507-1511. doi: 10. 1042/BST20120184

Conflict of Interest Statement: The authors declare that the research was conducted in the absence of any commercial or financial relationships that could be construed as a potential conflict of interest.

Copyright (C) 2018 Ghequire, Öztürk and De Mot. This is an open-access article distributed under the terms of the Creative Commons Attribution License (CC BY). The use, distribution or reproduction in other forums is permitted, provided the original author(s) and the copyright owner(s) are credited and that the original publication in this journal is cited, in accordance with accepted academic practice. No use, distribution or reproduction is permitted which does not comply with these terms. 